\title{
ULTRAFILTRATION OF BONE SAMPLES IS NEITHER THE PROBLEM NOR THE SOLUTION
}

\author{
Réka-Hajnalka Fülöp ${ }^{1,2} \cdot$ Stefan Heinze $^{3} \cdot$ Svetlana John$^{1} \bullet$ Janet Rethemeyer $^{1}$
}

ABSTRACT. We conducted analyses to identify the most suitable bone pretreatment protocol to be used by the recently established Radiocarbon Laboratory at the University of Cologne, CologneAMS. In 2 sets of analyses, we determined ${ }^{14} \mathrm{C}$ ages for subsamples taken from $3{ }^{14} \mathrm{C}$ bone standards (Oxford Mammoth, VIRI I, and VIRI H) complemented by age determinations of 12 unknown bone samples. Our results suggest that the strength and duration of the acid and alkali steps and the temperature of gelatinization might have a larger influence on the obtained ages than the presence or absence of ultrafiltration as a pretreatment step.

\section{INTRODUCTION}

The University of Cologne's Radiocarbon Laboratory became operational in 2010 (Dewald et al. 2013; Rethemeyer et al. 2013). Following the submission of the first bone samples for dating to this laboratory, we were confronted choosing from the different pretreatment protocols for bone and collagen extraction that are currently being used by well-established ${ }^{14} \mathrm{C}$ laboratories, and presented in the peer-reviewed literature. A summary of these methods is given in Table 1 . The list is not exhaustive and a quick search of the literature reveals even more variations in the duration of gelatinization and in the type and concentration of acids that are used (e.g. Gillespie et al. 1986; White et al. 2012).

Most ${ }^{14} \mathrm{C}$ dating laboratories use a modified version of Longin's (1971) bone pretreatment and collagen extraction method. Modifications include the duration of the acid and alkali steps (if an alkali step is included) and the strength of the acids and alkalis used, the duration and temperature of gelatinization, and whether ultrafiltration is used or not. The aim of the pretreatment is the removal of foreign carbon, nitrogen, and associated contamination that form covalent bonds with the collagen helix and most probably protect this during long-term burial (Collins et al. 2002).

In general, the method proposed by Longin (1971) fragments large peptides and extracts only $25 \%$ of the proteins. The depositional contaminants left behind after demineralization should be removed by the alkali (sodium hydroxide) treatment step (Gurfinkel 1987), but the alkali step may also cause a greater loss of collagen (Rudakova and Zaikov 1987; Yuan et al. 2000), and based on laboratory experience, when contamination is an issue, this step is skipped to increase the yield.

After gelatinization, the undissolved residue is removed by filtration (Longin 1971), which is done with different types of filters by different laboratories (Table 1). When ultrafiltration is part of the pretreatment protocol, these differ on how ultrafilters are being cleaned, the type of ultrafilters that are being used, and the molecular weight cut-off values that are chosen. Gel electrophoresis has shown that collagen extracted from fossil bones using weak acid has molecular weight fragments ranging between 4-100 kDa (Tuross et al. 1988) and so it is not clear what exactly the process of ultrafiltration will remove, especially in the case of degraded bone samples, where the usage of ultrafiltration would be the most important. The preferential selection of larger collagen peptides raises a number of questions (Bronk Ramsey et al. 2004; Higham et al. 2006; Brock et al. 2007; Hüls et al. 2007, 2009; Beaumont et al. 2010). For example, are shorter proteins fragmented collagen pro-

\footnotetext{
${ }^{1}$ Institute of Geology and Mineralogy, University of Cologne, 50674 Cologne, Germany.

${ }^{2}$ Corresponding author. Email: rfueloep@uni-koeln.de.

${ }^{3}$ Institute of Nuclear Physics, University of Cologne, 50674 Cologne, Germany.
} 
R-H Fülöp et al.

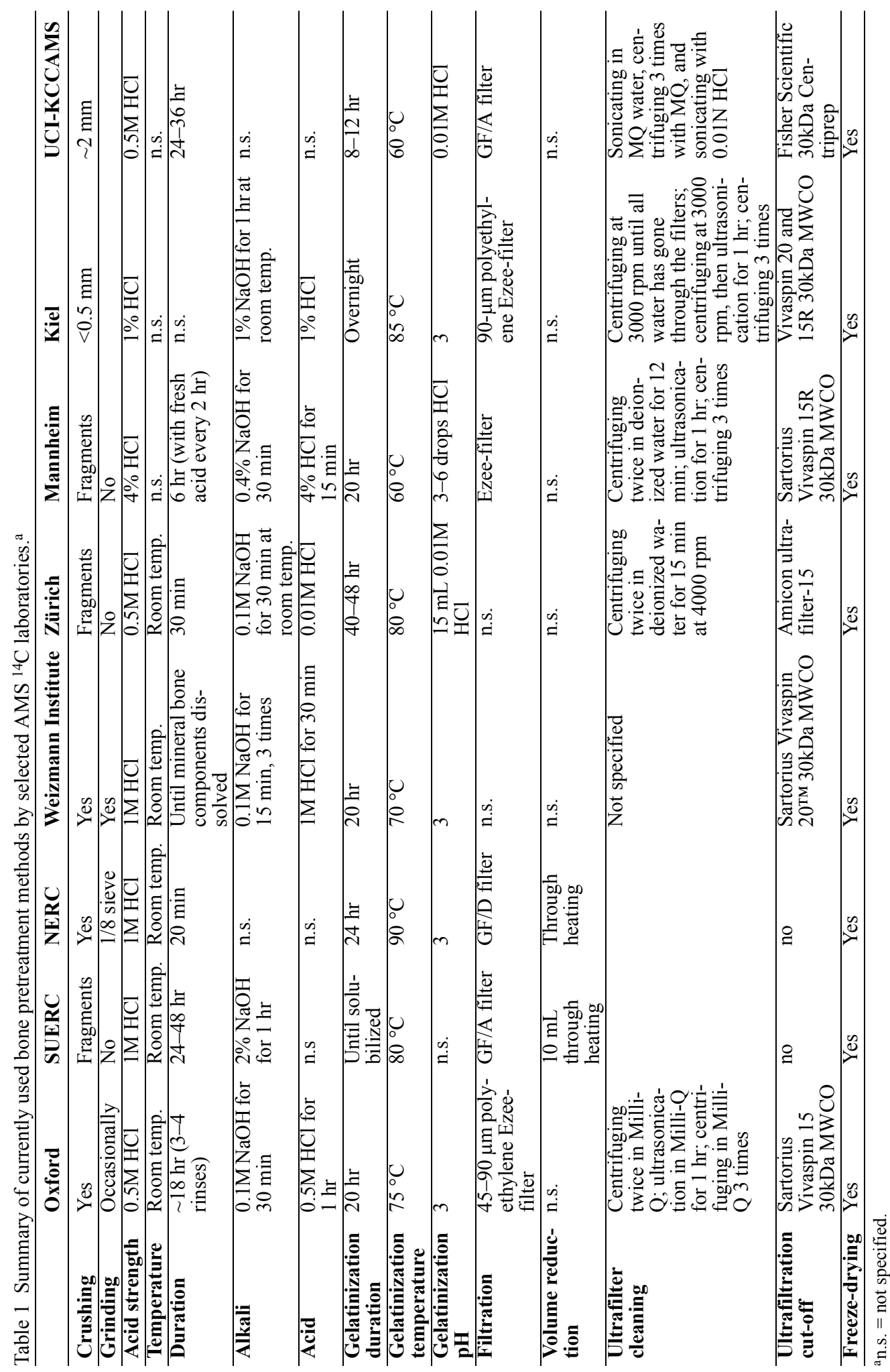




\section{Ultrafiltration is Neither the Problem nor Solution}

duced during pretreatment, or are these exogenous contaminants? What is an appropriate cut-off size? Does ultrafiltration contribute to the sample with modern or dead carbon contamination, and what is the best way to remove the manufacturer's protective glycerine from the ultrafilters? In addition to all of the above-mentioned analytical variations, results on bone samples are also complicated by factors such as burial conditions, soil $\mathrm{pH}$, moisture, and temperature, and the type of flora and microfauna that characterize the burial environment (Collins et al. 2002).

Here, we present the results of a series of analyses with standard material and bone samples of unknown age that we conducted in order to identify the most suitable bone pretreatment protocol for our new laboratory. We tested bone demineralization and collagen cleaning procedures by applying different acid and acid-base treatments as well as the use of ultrafiltration with 2 different cleaning methods of the ultrafilter membranes.

\section{METHODS}

We performed 2 sets of analyses. In the first set, we took subsamples from $3{ }^{14} \mathrm{C}$ bone standards including the Oxford Mammoth in-house standard Ox M (Lewis et al. 2006), VIRI I and VIRI H (Scott et al. 2007, 2010) and prepared each bone standard sample following 7 different pretreatment protocols (see Figure 1). For 2 of these standards (Ox M and VIRI H), in addition to the 7 age determinations, we have also determined ${ }^{14} \mathrm{C}$ ages for the ultrafilter eluent $(<30 \mathrm{kDa})$ fractions.

In the second set of analyses, we complement the analyses of bone standards with a further 12 unknown bone samples ranging in ${ }^{14} \mathrm{C}$ ages from 120 to $>50,000 \mathrm{yr}$ BP. For each of these bone samples, 2 subsamples were analyzed: one prepared without an ultrafiltration step and the other with ultrafiltration, respectively. All other pretreatment steps were kept the same. In addition, 3 of the unknown bone samples were treated with acid, the strength of which was reduced during the acid treatment step from $1 \mathrm{M} \mathrm{HCl}$ to $0.5 \mathrm{M} \mathrm{HCl}$. The pretreatment procedure in Cologne follows the hierarchical pretreatment steps outlined in Table 1 and discussed in detail below.

\section{Sample Cleaning}

For all samples processed (bone standards and unknown samples), $0.5-5 \mathrm{~g}$ of bone were cut from the original sample. The surface of this subsample was abraded with a diamond drill and cleaned twice with Milli- $\mathrm{Q}^{\mathrm{TM}}$ water in an ultrasonic bath for $15 \mathrm{~min}$. After drying, the sample was inspected under a microscope for any contamination that might have been introduced during handling (e.g. hair or fibers) and then crushed into 1-2 mm pieces. Following the cleaning step, the bone material was crushed into smaller fragments in order to speed up the dissolution in acid (Hajdas et al. 2009). We avoided grinding $(<0.5 \mathrm{~mm})$ as this might result in lower $\mathrm{C} / \mathrm{N}$ ratios and collagen with less than $10 \%$ protein content (Schöninger et al. 1989), and may cause fragmentation of collagen (NielsenMarsh et al. 2000). Further, considerable contamination can be introduced by handling and milling of the samples as a result of increasing the surface area of the sample, as observed on different materials following in-house tests (unpublished data).

\section{Acid and Alkali Steps}

All samples were subjected to an $\mathrm{HCl}$ treatment step. The duration and strength of this was varied among standard samples from 20 min to overnight (always at room temperature; see the Results section) and at least $3 \mathrm{hr}$ for unknown samples based on the reaction intensity between the bone and $\mathrm{HCl}$. Two aliquots of the standard bones were treated using an acid-alkali-acid extraction step (AAA) consisting of an acid treatment followed by leaching in $0.1 \%$ or $1 \% \mathrm{NaOH}$ for $15 \mathrm{~min}$ to $1 \mathrm{hr}$ 


\section{R-H Fülöp et al.}

(room temperature) followed by neutralizing with $1 \mathrm{M} \mathrm{HCl}$ and raising the $\mathrm{pH}$ to 3 with Milli-Q washes. In the case of 1 degraded bone (COL1837), the AAA extraction consisted of $1 \mathrm{M} \mathrm{HCl}$ acid treatment (A) overnight at room temperature, followed by $1 \% \mathrm{NaOH}$ for $4 \mathrm{hr}$ at $60{ }^{\circ} \mathrm{C}$, and neutralization by $1 \mathrm{M} \mathrm{HCl}$ for $1 \mathrm{hr}$ at room temperature.

\section{Gelatinization}

The gelatinization step (the solubilization of the collagen) suggested by Longin (1971) in order to produce a cleaner protein extract, consists of heated treatment with weak acid in which humates (insoluble at $90{ }^{\circ} \mathrm{C} / \mathrm{pH} 3$; Stafford et al. 1988) and particulate contaminants are removed by filtration (cf. Brown et al. 1988). This process is melting the collagen and so partially degrading it. In this study, the demineralized samples were treated with weak acid $(\mathrm{HCl}, \mathrm{pH} 3)$ while placed overnight in a heated $\left(60^{\circ} \mathrm{C}\right)$ shaking water bath.

\section{Filtration}

To remove particulate contaminants from solubilized collagen, Ezee-filters ${ }^{\mathrm{TM}}$ (Elkay Laboratory Products Ltd, UK) and glass fiber filters are the choice of particulate filter in most ${ }^{14} \mathrm{C}$ laboratories (Table 1). We used glass fiber filters (GF/D, $20 \mathrm{~mm} \varnothing$, Whatman $\left.{ }^{\mathrm{TM}}\right)$ that were precombusted at $450{ }^{\circ} \mathrm{C}$ for $4 \mathrm{hr}$ and placed in precombusted and heated glass syringes to minimize the risk of introducing more carbon contaminant. The hot collagen fraction was filtered through the GF filters and collected in precombusted glass vials.

\section{Ultrafiltration}

The procedure of ultrafiltration was first recommended by Brown et al. (1988) as an improvement to Longin's (1971) bone pretreatment method. In theory, collagen peptides are larger than the possible contaminants (mainly humic and fulvic acids), and so ultrafiltration will result in a separation of the two (Hedges and Law 1989; Hajdas et al. 2009). As part of this study, ultrafiltration was applied to both standards and unknown samples. The bone standards (Ox M, VIRI I, VIRI H) were ultrafiltered with Sartorius Vivaspin ${ }^{\circledR}$ 15, Pall Macrosep ${ }^{\circledR}$ Advance, and Millipore Amicon Ultra-15 ultrafilters with a molecular cut-off value of $30 \mathrm{kDa}$. For 2 of the bone standards (Ox M, VIRI H), both ultrafiltered fractions, i.e. $>30 \mathrm{kDa}$ and $<30 \mathrm{kDa}$, were also dated. All unknown samples were ultrafiltered with Sartorius Vivaspin 15, with a molecular cut-off value of $30 \mathrm{kDa}$, since sample handling in the case of the Sartorius ultrafilters was more convenient.

Some $24 \mathrm{hr}$ prior to ultrafiltration, the ultrafilters were cleaned following Brock et al. (2007) and Beaumont et al. (2010) by sonication in a large volume of Milli-Q water for $1 \mathrm{hr}$, then centrifuged 3 times $(2300 \mathrm{rpm}, 5 \mathrm{~min}$ ) followed by a sonication in $0.01 \mathrm{M} \mathrm{HCl}$ for at least $15 \mathrm{~min}$ and centrifuged again 3 more times in Milli-Q water (2300 rpm, $5 \mathrm{~min}$ ). Following this cleaning procedure, the ultrafilters were kept wet to prevent them from drying out. Later in this study, the cleaning procedure described above was modified following Svyatko et al. (2012) by adding a heating step during sonication, where filters were cleaned in $70^{\circ} \mathrm{C}$ Milli-Q water for $1 \mathrm{hr}$ instead at room temperature. The individual pretreatment methods that were applied to each standard and unknown sample are summarized in Figures 1 and 2 and are described in the next section.

Following pretreatment, samples were freeze-dried and converted into AMS graphite cathodes by combustion in an elemental analyzer (Vario Micro Cube, Elementar, Germany) coupled to an automated graphitization system as outlined in Rethemeyer et al. (2013). The AMS measurements were performed with the 6MV Tandetron AMS at Cologne University (Dewald et al. 2013). 


\section{Ultrafiltration is Neither the Problem nor Solution}

\section{RESULTS AND DISCUSSION}

Figure 1 shows the results for 7 samples taken from each of the 3 bone standards. Each sample was processed following a slightly different acid (A) or acid-alkali-acid (AAA) treatment step, but keeping the cleaning, gelatinization, and particulate filtration steps uniform. Ultrafiltration was included for at least 1 aliquot from each of the standards.

For samples (1) and (2) in Figure 1, we included alkali steps with 1 and $0.1 \%$ concentration and varied the acid treatment time and concentration. Samples (3), (4), and (7) were not treated with $\mathrm{NaOH}$ but the acid treatment duration was varied, while the concentration was kept constant. In the case of (7), and (8) new acid solution was added after $3 \mathrm{hr}$ of decalcification time ( $3 \mathrm{hrs}+3 \mathrm{hrs}$ in Figure 1) instead of keeping the same acid solution as in the case of the rest of the samples. Samples (5) and (8) are aliquots of samples (4) and (7), respectively, and had ultrafiltration included in the pretreatment procedure. Samples (6) and (9) are the results for the corresponding $<30 \mathrm{kDa}$ protein fragments of samples (5) and (8) that passed through the ultrafilters. Ultrafilters were cleaned as described in the method section without including the $70{ }^{\circ} \mathrm{C}$ heating step during sonication.
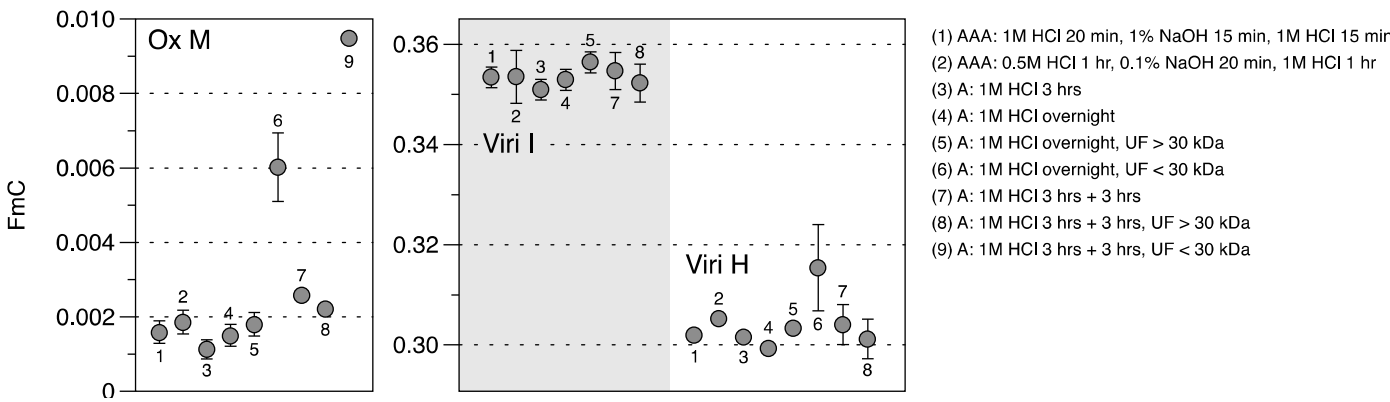
(2) AAA: $0.5 \mathrm{M} \mathrm{HCl} 1 \mathrm{hr}, 0.1 \% \mathrm{NaOH} 20 \mathrm{~min}, 1 \mathrm{M} \mathrm{HCl} 1 \mathrm{hr}$ (3) A: $1 \mathrm{M} \mathrm{HCl} 3 \mathrm{hrs}$ (4) $\mathrm{A}: 1 \mathrm{M} \mathrm{HCl}$ overnight (5) A: $1 \mathrm{M} \mathrm{HCl}$ overnight, $U F>30 \mathrm{kDa}$ (6) A: $1 \mathrm{M} \mathrm{HCl}$ overnight, $\mathrm{UF}<30 \mathrm{kDa}$ (7) A: $1 \mathrm{M} \mathrm{HCl} 3 \mathrm{hrs}+3 \mathrm{hrs}$ (8) A: $1 \mathrm{M} \mathrm{HCl} 3 \mathrm{hrs}+3 \mathrm{hrs}, \mathrm{UF}>30 \mathrm{kDa}$ (9) $\mathrm{A}: 1 \mathrm{M} \mathrm{HCl} 3 \mathrm{hrs}+3 \mathrm{hrs}, \mathrm{UF}<30 \mathrm{kDa}$

Figure 1 Summary of results obtained following different pretreatment methods applied to standard bone materials prior to gelatinization, filtration, and freeze-drying. The standard materials used are the following: Oxford Mammoth (>147 kyr); VIRI I $(0.30 \pm 0.0003 \mathrm{Fm})$; and VIRI H $(0.36 \pm 0.0003 \mathrm{Fm})$. Uncertainties are given at the $1 \sigma$ level.

Despite the different pretreatment protocols (excluding the $<30 \mathrm{kDa}$ fraction) used in our study and variations seen in the data, the results for all bone standards overlap at the $2 \sigma$ level, and therefore are statistically indistinguishable. Similar results were obtained for the 12 unknown bone samples (Figure 2). Here, the dates obtained for the ultrafiltered subsamples are also statistically not different from those obtained for the other treatment protocols, although the ultrafilters have been cleaned with hot water as well.

In previous studies, the choice of acid strength and the duration of the acid step and later gelatinization conditions greatly influenced the yield of the collagen and the amount of larger collagen peptides that were present (e.g. Tuross et al. 1988; Semal and Orban 1995; Caputo et al. 2012). The amount of larger amino acid molecules is considered to be an indicator of collagen preservation. The larger collagen molecules should yield a more reliable age given that the shorter molecules are mainly degraded collagen and the larger but contaminated molecules - with humic and fulvic acids of soil origin, polyphenols, polysaccharides, lignins - should be broken off during pretreatment (Ambrose 1990; Ambrose and Krigbaum 2003; Hajdas et al. 2009). In the case of the 3 unknown bone samples that were processed using both $0.5 \mathrm{M}$ and $1 \mathrm{M} \mathrm{HCl}$ acid steps at room temperature, those samples that were demineralized with the weaker acid (i.e. $0.5 \mathrm{M} \mathrm{HCl}$ ) produced about $\sim 50 \%$ higher collagen yields (not quantified for all samples). In contrast, those demineralized with 


\section{R-H Fülöp et al.}

$1 \mathrm{M} \mathrm{HCl}$ yielded a greater amount of dissolved collagen as suggested by others (Arslanov and Svezhetsev 1993; Beaumont et al. 2010), especially in the case of degraded bone material. The ${ }^{14} \mathrm{C}$ ages of decalcified samples with 2 different concentrations of $\mathrm{HCl}$ did not yield statistically different values. Our tests were performed at room temperature, but to minimize the destruction of the collagen during demineralization one could also consider procedures at low temperatures $\left(4{ }^{\circ} \mathrm{C}\right)$ and weak acids (0.5-0.6M HCl) (Koon et al. 2003, based on Collins and Galley 1998; Buckley et al. 2010,2011 ). The ages obtained for the standard samples (Figure 1) treated with $\mathrm{NaOH}$ solution are all younger than those obtained for the only acid-treated samples and therefore alkali treatment does not improve the results.

There are several potential problems associated with the method of ultrafiltration, which are discussed in more detail below. Similar to the usage of strong acid and alkali solutions, ultrafiltration will decrease the yield of collagen. The main problem with ultrafiltration, however, is not just the decreased yield and possibility of losing precious sample material, but rather the uncertainty surrounding sample contamination by glycerine and the material making up the filter membrane. The latter is especially important given that sample sizes used in ${ }^{14} \mathrm{C}$ dating are getting smaller and smaller and so the determined ages are becoming highly sensitive to even the smallest amounts of contamination (Vogel et al. 1987; Santos et al. 2010).

In the case of glycerine, the soluble humectant used for protecting the filters from drying out can have a varying carbon source origin. The source of carbon can either be modern or fossil (Hüls et al. 2007, 2009; Wood et al. 2010) and can vary with each batch (Brock et al. 2007). This variation requires a continuous monitoring of the ultrafilters, adding additional time and cost to the sample preparation. The addition of only $1 \%$ modern carbon to a sample that initially contained no ${ }^{14} \mathrm{C}$, for example, will yield an apparent age of $37 \mathrm{ka}$ BP. In contrast, the addition of fossil carbon will only slightly affect the obtained age (Wood et al. 2010; Talamo 2012). For aliquots of bone standard $\mathrm{Ox} \mathrm{M}$, we analyzed both ultrafiltered fractions (i.e. larger and smaller than $30 \mathrm{kDa}$ ) and in both cases we obtained a difference of $10-12 \mathrm{kyr}$ between the $<30 \mathrm{kDa}$ and $>30 \mathrm{kDa}$ fractions, respectively $(5$, 6 and 8, 9 in Figure 1). The ultrafilter eluent $(<30 \mathrm{kDa})$ fraction of sample Ox M yielded ages of $37,426 \pm 212$ and $41,073 \pm 1228 \mathrm{yr} \mathrm{BP}$, equivalent to roughly $1 \mathrm{mg}$ of modern carbon contamination in both cases. The $>30 \mathrm{kDa}$ ultrafilter fraction yielded ages of 50,813 \pm 1414 and 49,108 $\pm 661 \mathrm{yr} \mathrm{BP}$, respectively. The above can either mean that (1) the younger fraction of the sample is removed by the ultrafilter, or (2) the sample is substantially contaminated by the glycerine protecting the ultrafilters, considering that we are dealing with samples that are small (starting weight $<2 \mathrm{~g}$ ) and ${ }^{14} \mathrm{C}$ free. Given that we obtain older ages for all aliquots for which ultrafiltration is not performed (Figure 1: samples $1,2,3,4,7)$ suggests that contamination by the glycerine protecting the ultrafilters is the likely explanation for the age difference obtained and that our initial cleaning procedure based on Brock et al. (2007) and Beaumont et al. (2010) did not remove all coatings from the ultrafilters. To improve our ultrafilter cleaning procedure, we introduced a heating step $\left(70{ }^{\circ} \mathrm{C}\right)$ during the sonication of the ultrafilters, in the hope that this step will remove the ultrafilter coatings (Svyatko et al. 2012). Analyses on 6 of the unknown samples ranging from young to old samples, done after the modification to the ultrafilter cleaning procedure (Table 2), produced results that were not significantly different from those obtained for the non-ultrafiltered pairs.

In our study, more accurate ages are obtained when only $\mathrm{HCl}$ pretreatment ( 3 and 4 in Figure 1) is applied to the samples before gelatinization, filtration, and freeze-drying. The tests involving ultrafiltration (5-6 and 8-9 in Figure 1) were repeated with slightly different acid step duration and yielded younger ages than previously for Ox M, suggesting that the obtained differences in ages 


\section{Ultrafiltration is Neither the Problem nor Solution}

Table 2 Results for samples processed with ultrafilters (Sartorius Vivaspin 15) with and without including the heating step $\left(70^{\circ} \mathrm{C}\right)$ during ultrafilter cleaning procedure. Note how the age difference between the ultrafiltered samples versus the non-ultrafiltered samples varies, but does not follow any trend (i.e. results are sometimes younger and sometimes older).

\begin{tabular}{|c|c|c|c|c|c|}
\hline Sample name & Fm & $\pm 1 \sigma$ & Age (yr BP) & $\pm 1 \sigma$ & Pretreatment method \\
\hline \multicolumn{6}{|c|}{ Before cleaning UF with $70^{\circ} \mathrm{C}$ water } \\
\hline COL1250.1.1 & 0.815 & 0.002 & 1644 & 21 & $1 \mathrm{M} \mathrm{HCl}$ overnight \\
\hline COL1250.2.1 & 0.813 & 0.004 & 1663 & 28 & $1 \mathrm{M} \mathrm{HCl}$ overnight, $\mathrm{UF}>30 \mathrm{kDa}$ \\
\hline COL1568.1.1 & 0.020 & 0.001 & 31,448 & 200 & $1 \mathrm{M} \mathrm{HCl}$ overnight \\
\hline COL1568.2.1 & 0.019 & 0.001 & 31,678 & 119 & $1 \mathrm{M} \mathrm{HCl}$ overnight, $\mathrm{UF}>30 \mathrm{kDa}$ \\
\hline COL1569.1.1 & 0.172 & 0.001 & 14,149 & 57 & $1 \mathrm{M} \mathrm{HCl}$ overnight \\
\hline COL1569.2.1 & 0.173 & 0.005 & 14,111 & 41 & $1 \mathrm{M} \mathrm{HCl}$ overnight, $\mathrm{UF}>30 \mathrm{kDa}$ \\
\hline \multicolumn{6}{|c|}{ After cleaning UF with $70^{\circ} \mathrm{C}$ water } \\
\hline COL1827.1.2 & $>$ det. limit & n.a. & $>55,000$ & n.a. & $1 \mathrm{M} \mathrm{HCl}$ overnight \\
\hline COL1827.2.2 & $>$ det. limit & n.a. & $>55,000$ & n.a. & $1 \mathrm{M} \mathrm{HCl}$ overnight, $\mathrm{UF}>30 \mathrm{kDa}$ \\
\hline COL1989.1.1 & 0.004 & 0.003 & 44,038 & 661 & $1 \mathrm{M} \mathrm{HCl}$ overnight \\
\hline COL1989.4.1 & 0.004 & 0.003 & 44,428 & 690 & $1 \mathrm{M} \mathrm{HCl}$ overnight, $\mathrm{UF}>30 \mathrm{kDa}$ \\
\hline COL1996.1.1 & 0.007 & 0.004 & 40,090 & 452 & $1 \mathrm{M} \mathrm{HCl}$ overnight \\
\hline COL1996.3.1 & 0.006 & 0.004 & 40,614 & 488 & $1 \mathrm{M} \mathrm{HCl}$ overnight, $\mathrm{UF}>30 \mathrm{kDa}$ \\
\hline COL1667.1.1 & 0.692 & 0.003 & 2962 & 40 & $1 \mathrm{M} \mathrm{HCl}$ overnight \\
\hline COL1667.2.1 & 0.713 & 0.004 & 2714 & 40 & $1 \mathrm{M} \mathrm{HCl}$ overnight, $\mathrm{UF}>30 \mathrm{kDa}$ \\
\hline COL1841.1.1 & 0.985 & 0.005 & 118 & 37 & $1 \mathrm{M} \mathrm{HCl}$ overnight \\
\hline COL1841.2.1 & 0.984 & 0.004 & 133 & 36 & $1 \mathrm{M} \mathrm{HCl}$ overnight, $\mathrm{UF}>30 \mathrm{kDa}$ \\
\hline
\end{tabular}

(overlapping at the $2 \sigma$ level) could be due to sometimes overlooked human error or AMS measurement variability. Despite this, ultrafiltration increases sample handling and also the chance of introducing more contamination than what it actually removes especially with the current filter material.

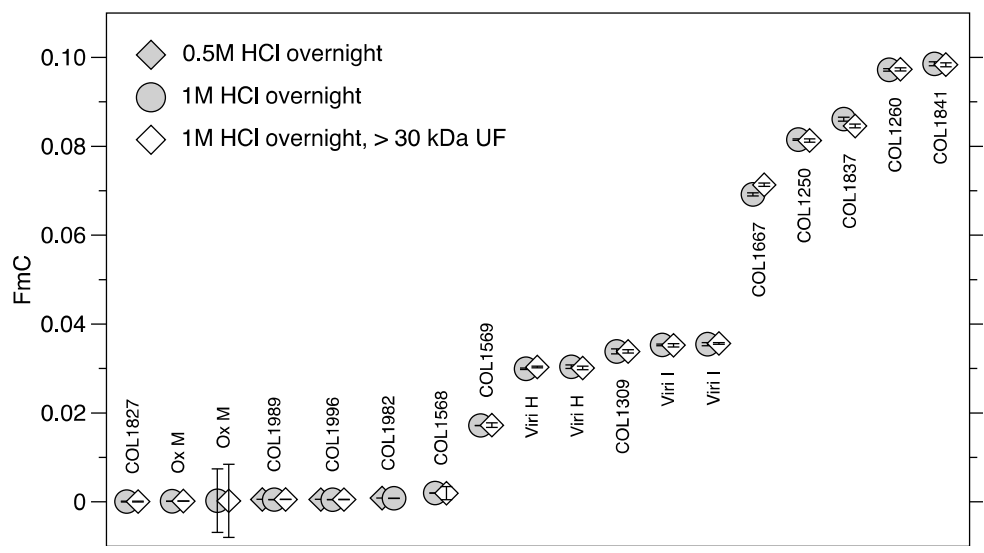

Figure 2 Summary of Fm values obtained for bone standard and unknown samples following 3 pretreatment protocols by varying the acid step only: $0.5 \mathrm{M} \mathrm{HCl}$ (dark diamonds); $1 \mathrm{M} \mathrm{HCl}$ (circles); and $1 \mathrm{M} \mathrm{HCl}$ plus ultrafiltration (open diamonds).

As shown in Figure 2, ultrafiltration did not yield statistically different ages across the wide range of fraction modern of carbon (Fm) values covered with our sample set compared to the values 


\section{R-H Fülöp et al.}

obtained for the aliquots that were only treated with $1 \mathrm{M} \mathrm{HCl}$, gelatinized, filtered and lyophilized. Ultrafiltration is required in cases where bone is greatly degraded and therefore also greatly contaminated; however, the degraded bone samples remain under-reported in the literature. One of the young bone samples that we analyzed (COL1837) was severely degraded. Three subsamples of COL1837 were analyzed following 3 different pretreatment protocols that produced statistically different ages (Table 3 ). The bone had an expected age of $\sim 800$ cal yr BP (provided by the submitter) and was additionally analyzed by the Klaus-Tschira-Laboratory in Mannheim, Germany. The different amounts of C (Table 3) and the different ages obtained for this sample support the view that the different pretreatment methods radically change the results for degraded bone. We suggest that in the case of this sample, either (1) the contamination is old and was not removed by the ultrafiltration step in neither of the 2 laboratories given that the AAA treatment yielded an older age, or (2) old contamination was added during ultrafiltration from cellulose-filter membranes or glycerine produced from fossil carbon source materials if the only $\mathrm{HCl}$ treated sample (A) is valid.

Table 3 Results obtained for bone sample COL1837. ${ }^{\mathrm{a}}$

\begin{tabular}{llccccccc}
\hline AMS ID & Pretreatment & $\mathrm{N}(\%)$ & $\mathrm{C}(\%)$ & $\mathrm{C} / \mathrm{N}$ & Fm & $\pm 1 \sigma$ & Age $(\mathrm{yr}$ BP) & $\pm 1 \sigma$ \\
\hline & Raw bone & 0.9 & 5.3 & 5.5 & & & $\sim 800$ & \\
s01192 & A & 7.4 & 20.7 & 2.8 & 0.861 & 0.005 & 1200 & 43 \\
s01193 & A+UF & 10.4 & 29.4 & 2.8 & 0.846 & 0.004 & 1346 & 40 \\
s01194 & AAA & 5.2 & 15.1 & 2.9 & 0.835 & 0.005 & 1545 & 47 \\
MAMS 16124b & AAA+UF & n.a. & 11.5 & 3.4 & 0.857 & 0.002 & 1260 & 18 \\
\hline
\end{tabular}

${ }^{a}$ In the Cologne laboratory the acid treatment (A) consist of $1 \mathrm{M} \mathrm{HCl} \mathrm{overnight} \mathrm{at} \mathrm{room} \mathrm{temperature,} \mathrm{the} \mathrm{acid-alkali-acid}$ treatment (AAA) consist of $1 \mathrm{M} \mathrm{HCl}$ overnight, $1 \% \mathrm{NaOH}$ for $4 \mathrm{hr}$ at $60^{\circ} \mathrm{C}$ and followed by $1 \mathrm{M} \mathrm{HCl}$ for $1 \mathrm{hr}$ at room temperature. In case of A+UF, same as A only the sample has been ultrafiltered.

${ }^{\mathrm{b}}$ The protocol used by the Mannheim laboratory is given in Table 1 .

The ultrafiltration should improve the pretreatment procedure of bone samples by selecting the larger peptides. But if bone is sensitive to different burial and diagenetic conditions - these factors being temperature, $\mathrm{pH}$, and demineralization - these should matter during pretreatment as well. Both acid strength and decalcification time and maybe temperature as well, determine the size of peptides in the final freeze-dried product (Semal and Orban 1995). In the case of well-preserved collagen, the alkali treatment step will not influence the age of the sample (Gillespie et al. 1986), but as shown by Hajdas et al. (2009), in the case of old bones the alkali step could substitute ultrafiltration. Given that the solubility of degraded collagen dramatically increases when the strength of sodium hydroxide $(\mathrm{NaOH})$ is above $0.1 \mathrm{M}$, the alkali step will most likely be skipped in the case of badly degraded bone samples, despite this treatment step being more important for these than for fresh bone. According to Arslanov and Svezhetsev (1993), the humic compounds or contamination are highly polymerized and nearly insoluble by alkali treatment at room temperature, and so temperature might be an important factor in the performance of the alkali treatment step also (i.e. room temperature only degrading the collagen rather removing the contamination). The heating temperature and duration of the gelatinization step might be as important as the demineralization step temperature in terms of the final collagen product (Xiong 2008). Based on yield tests, heating the collagen above $58^{\circ} \mathrm{C}$ is unnecessary (Brown et al. 1988). Brown et al. (1988) also found that after heating to $90^{\circ} \mathrm{C}$, no collagen fraction $>10 \mathrm{kDa}$ remains present, and Semal and Orban (1995) have argued that shortening the duration of gelatinization to $50 \mathrm{~min}$ and increasing the temperature to $90{ }^{\circ} \mathrm{C}$ will result in no fragmentation; rather the yield of larger peptides will increase. There is no real consensus in the literature on the effects of gelatinization on the final collagen product and so further work in necessary in this area. 


\section{CONCLUSION}

The result of our study shows that ultrafiltration did not yield statistically different ages across the full range of Fm values in comparison to the values obtained for the subsamples that were only treated with $1 \mathrm{M} \mathrm{HCl}$, gelatinized, filtered, and lyophilized. The higher and variable ${ }^{14} \mathrm{C}$ content of the Sartorius Vivaspin 15 membrane that was used in our study (and also used by most laboratories), and the uncertainty surrounding the completeness of the removal of all contaminants from the ultrafilters, raises the question as to whether it is adequate to apply ultrafiltration if this does not make a statistically significant difference.

Our tests also show that acid-alkali-acid (AAA) treatment duration, strength, and temperature can introduce variations in the ${ }^{14} \mathrm{C}$ age that are even larger than those introduced by the process of ultrafiltration. Given that the duration and temperature of gelatinization was uniform for all samples, the obtained changes in Fm values occur mainly due to AAA pretreatment variations and ultrafiltration. However, if one is to obtain larger collagen peptides at the end of the gelatinization process so that ultrafiltration can be skipped with more confidence, one should consider changing to a shorter and more intensive gelatinization process.

The method has reached a point where sample size and AMS precision are no longer the limiting factors; rather, human error during pretreatment and sample handling will play a key role in delivering the expected accuracy of bone ${ }^{14} \mathrm{C}$ dating. Thus, future attempts to find the likely causes of unexpected results should also consider the human element in the analysis process. Although the aim of bone ${ }^{14} \mathrm{C}$ dating is to establish only the age of the bone, the composition of the bone, the burial environment, and the diagenesis processes cannot be completely ignored, as these can have an effect on the pretreatment protocol that is chosen and can also substantially influence the resulting ${ }^{14} \mathrm{C}$ age.

\section{ACKNOWLEDGMENTS}

We are grateful to M E Scott, P Naysmith, and F Brock for providing standard and old bone material. We thank S Lindauer for dating the COL1837 bone and for her guidance during the initial setup of our laboratory, and E Dunbar and C Bryant for sharing their collagen extraction protocols. We thank $\mathrm{U}$ Patt for assistance with graphitization, and N Mantke for elemental analyses.

\section{REFERENCES}

Ambrose SH. 1990. Preparation and characterization of bone and tooth collagen for isotopic analysis. Journal of Archaeological Science 17(4):431-51.

Ambrose SH, Krigbaum J. 2003. Bone chemistry and bioarchaeology. Journal of Anthropological Archaeology 22(3):193-9.

Arslanov KA, Svezhentsev YS. 1993. An improved method for radiocarbon dating fossil bones. Radiocarbon 35(3):387-91.

Beaumont W, Beverly R, Southon J, Taylor RE. 2010. Bone preparation at the KCCAMS laboratory. $\mathrm{Nu}$ clear Instruments and Methods in Physics Research B 268(7-8):906-9.

Brock F, Bronk Ramsey C, Higham TFG. 2007. Quality assurance of ultrafiltered bone dating. Radiocarbon 49(2):187-92.

Bronk Ramsey C, Higham T, Bowles A, Hedges R. 2004. Improvements to the pretreatment of bone at Oxford. Radiocarbon 46(1):155-63.
Brown TA, Nelson DE, Vogel JS, Southon JR. 1988. Improved collagen extraction by modified Longin method. Radiocarbon 30(2):171-7.

Buckley M, Whitcher Kansa S, Howard S, Campbell S, Thomas-Oates J, Collins M. 2010. Distinguishing between archaeological sheep and goat bones using a single collagen peptide. Journal of Archaeological Science 37(1):13-20.

Buckley M, Larkin N, Collins M. 2011. Mammoth and mastodon collagen sequences; survival and utility. Geochimica et Cosmochimica Acta 75(7):2007-16.

Caputo I, Lepretti M, Scarabino C, Esposito C, Proto A. 2012. An acetic acid-based extraction method to obtain high quality collagen from archeological bone remains. Analytical Biochemistry 421(1):92-6.

Collins MJ, Riley MS, Child AM, Turner-Walker G. 1995. A basic mathematical simulation of the chemical degradation of ancient collagen. Journal of Archaeological Science 22(2):175-83. 


\section{R-H Fülöp et al.}

Collins MJ, Galley P. 1998. Towards an optimal method of archaeological collagen extraction; the influence of $\mathrm{pH}$ and grinding. Ancient Biomolecules 2:209-22.

Collins MJ, Nielsen-Marsh CM, Hiller J, Smith CI, Roberts JP, Prigodich RV, Wess TJ, Csapò J, Millard AR, Turner-Walker G. 2002. The survival of organic matter in bone: a review. Archaeometry 44(3):383-94.

Dewald A, Heinze S, Jolie J, Zilges A, Dunai T, Rethemeyer J, Melles M, Staubwasser M, Kuczewski B, Richter J, Radtke U, von Blanckenburg F, Klein M. 2013. CologneAMS, a dedicated Center for Accelerator Mass Spectrometry in Germany. Nuclear Instruments and Methods in Physics Research B 294:18-23.

Gillespie R, Hedges REM, Humm MJ. 1986. Routine AMS dating of bone and shell proteins. Radiocarbon 28(2A):451-6.

Gurfinkel DM. 1987. Comparative study of the radiocarbon dating of different bone collagen preparations. Radiocarbon 29(1):45-52.

Hajdas I, Michczyński A, Bonani G, Wacker L, Furrer H. 2009. Dating bones near the limit of the radiocarbon dating method: study case mammoth from Niederweningen, ZH Switzerland. Radiocarbon 52(2):675-80.

Hedges REM, Law IA. 1989. The radiocarbon dating of bone. Applied Geochemistry 4(3):249-53.

Higham TFG, Jacobi RM, Bronk Ramsey C. 2006. AMS radiocarbon dating of ancient bone using ultrafiltration. Radiocarbon 48(2):179-95.

Hüls CM, Grootes PM, Nadeau M-J. 2007. How clean is ultrafiltration cleaning of bone collagen? Radiocarbon 49(2):193-200.

Hüls CM, Grootes PM, Nadeau M-J. 2009. Ultrafiltration: boon or bane? Radiocarbon 51(2):613-26.

Koon HEC, Nicholson RA, Collins MJ. 2003. A practical approach to the identification of low temperature heated bone using TEM. Journal of Archaeological Science 30(11):1393-9.

Lewis SG, Maddy D, Buckingham C, Coope GR, Field MH, Keen DH, Pike AWG, Roe DA, Scaife RG, Scott K. 2006. Pleistocene fluvial sediments, palaeontology and archaeology of the upper River Thames at Latton, Wiltshire, England. Journal of Quaternary Science 21(2):181-205.

Longin R. 1971. New method of collagen extraction for radiocarbon dating. Nature 230(5291):241-2.

Nielsen-Marsh CM, Hedges REM, Mann T, Collins MJ. 2000. A preliminary investigation of the application of differential scanning calorimetry to the study of collagen degradation in archaeological bone. Thermochimica Acta 365(1-2):129-39.

Rethemeyer J, Fülöp R-H, Höfle S, Wacker L, Heinze S, Hajdas I, Patt U, König S, Stapper B, Dewald A. 2013. Status report on sample preparation facilities for ${ }^{14} \mathrm{C}$ analysis at the new CologneAMS center. Nuclear Instruments and Methods in Physics Research B 294: $168-72$.

Rudakova TE, Zaikov GE. 1987. Degradation of col- lagen and its possible applications in medicine. Polymer Degradation and Stability 18:271-91.

Santos GM, Southon JR, Drenzek NJ, Ziolkowski LA Druffel E, Xu X, Zhang D, Trumbore S, Eglinton TI, Hughen KA. 2010. Blank assessment for ultra-small radiocarbon samples: chemical extraction and separation versus AMS. Radiocarbon 52(2):1322-35.

Schöninger MJ, Moore KM, Murray ML, Kingston JC. 1989. Detection of bone preservation in archeological and fossil samples. Applied Geochemistry 4:281-92.

Scott EM, Cook GT, Naysmith P, Bryant C, O'Donnell D. 2007. A report on Phase 1 of the 5th International Radiocarbon Intercomparison (VIRI). Radiocarbon 49(2):409-26.

Scott EM, Cook GT, Naysmith P. 2010. A report on phase 2 of the Fifth International Radiocarbon Intercomparison (VIRI). Radiocarbon 52(3):846-58.

Semal P, Orban R. 1995. Collagen extraction from recent and fossil bones quantitative and qualitative aspects. Journal of Archaeological Science 22(4):463-7.

Stafford Jr TW, Brendel K, Duhamel RC. 1988. Radiocarbon, ${ }^{13} \mathrm{C}$ and ${ }^{15} \mathrm{~N}$ analysis of fossil bone: removal of humates with XAD-2 resin. Geochimica et Cosmochimica Acta 52(9):2257-67.

Svyatko SV, Hoper ST, Reimer PJ. 2012. The use of hotwashed Vivaspin $^{\mathrm{TM}}$ filters for pretreatment of bone collagen for radiocarbon and stable isotope analyses: a revised Bronk Ramsey et al. (2004) methodology. Radiocarbon Conference 2012, Paris. S03-P-035.

Talamo S. 2012. Refining ${ }^{14} \mathrm{C}$ dating of bone $>30,000$ BP: establishing an accurate chronology for the Middle to Upper Palaeolithic transition in France $[\mathrm{PhD}$ thesis]. Faculty of Archaeology, Leiden University.

Tuross N, Fogel ML, Hare PE. 1988. Variability in preservation of the isotopic composition of collagen from fossil bone. Geochimica et Cosmochimica Acta 52(9): 929-35.

Vogel JS, Nelson DE, Southon J. 1987. ${ }^{14} \mathrm{C}$ background levels in an AMS system. Radiocarbon 29(3):323-33.

White R, Mensan R, Bourrillon R, Cretin C, Higham TFG, Clark AE, Sisk ML, Tartar E, Gardère P, Goldberg P, Pelegrin J, Valladas H, Tisnérat-Laborde N, de Sanoit J, Chambellan D, Chiotti L. 2012. Context and dating of Aurignacian vulvar representations from Abri Castanet, France. Proceedings of the National Academy of Sciences 109(22):8450-5.

Wood RE, Bronk Ramsey C, Higham TFG. 2010. Refining background corrections for radiocarbon dating of bone collagen at ORAU. Radiocarbon 52(2):600-11.

Xiong X. 2008. New insights into structure and function of Type I collagen [PhD thesis]. Institute for Interfacial Engineering at the University of Stuttgart.

Yuan S, Wu X, Gao S, Wang J, Cai L, Liu K, Li K, Ma H. 2000. Comparison of different bone pretreatment methods for AMS ${ }^{14} \mathrm{C}$ dating. Nuclear Instruments and Methods in Physics Research B 172(1-4):424-7. 